Review article

\title{
Mucormycosis: A deadly black fungus infection among COVID-19 patients in India
}

\author{
Naveen Kumar Choudhary ", Amit K. Jain, Rupesh Soni, Neha Gahlot \\ B R Nahata College of Pharmacy, Mandsaur University, Mandsaur, 458001, India
}

\section{A R T I C L E I N F O}

\section{Keywords:}

COVID-19

Mucormycosis

Black fungus

Hyperglycemia

Immunosuppressant

\begin{abstract}
A B S T R A C T
After first phase of Covid-19, the second wave affects a lot to the Indians with mysterious fungal infection known as Mucormycosis. Here, we reviewed clinical pathogenesis, signs, symptoms and treatment against black fungus. The conclusion revealed that use of immunosuppressant to combat Covid-19 also increases the risk to get infected with mucormycosis. Patients with hyperglycemia, ketoacidosis, solid organ or bone marrow transplantion, liver cirrhosis, neutropenia are more susceptible to get attacked by Mucormycosis moulds. Early diagnosis, removal of predisposing factors, timely antifungal therapy with surgical removal of all infected tissues and adjunctive therapies are four major factors to eradicate Mucormycosis.
\end{abstract}

\section{Introduction}

India affects a lot with the worldwide pandemic Covid-19 caused by "Severe acute respiratory syndrome Corona virus-2 (SARS-CoV-2)". ${ }^{1}$ First case of COVID-19 was reported in Kerala, India on 30th January 2020, afterwards highest cases i.e. 1 lakhs per day were reported for the year by May $2020 .^{2}$ After mid June recovery of patient's increases successively with decrease in infection rate, further active case dropped to less than 15000 in January 2021. Afterwards second wave was begun in March 2021 with a larger blow of active cases then first wave with deficiency of hospital beds, vaccines, medicines, oxygen cylinders and oxygen. The daily reported cases were reached to around 4.5 lakhs in starting of May 2021. ${ }^{3}$ The effect of Covid-19 ranges from mild to moderate to life threatening with some associated disorders such as diabetes mellitus, cardiac diseases and immune compromised conditions. ${ }^{4,5}$ Research articles also reported about the development of severe opportunistic infectious diseases like pneumonia, candidiasis, pulmonary aspergillosis etc in Covid-19 affected patients. ${ }^{6,7}$ There are also reports of development of mysterious fungal infection known as Mucormycosis or Black fungus in Covid-19 patients. $^{8}$ Covid-19 patients in India also suffer with this epidemic disease (mucormycosis) with a reported case of 8848 till May 22, 2021. ${ }^{9}$ Here the current article reports signs, symptoms, diagnosis, treatment, prevention against black fungus.

\section{Mucormycosis or black fungus}

Mucormycosis is also termed as black fungus due to the necrosis of affected tissue of patient's skin which turns it into black. "Mucormycosis" is the rarest type of fungal infection in order of importance after candidiasis and aspergillosis. It caused by Mucormycetes belong to the class Zygomycetes having order Mucorales. The mucormycetes mould mainly occurs in soil, leaves, decayed wood, manure etc. Species of Mucoraceae family i.e Rhizopus arrhizus, Rhizopus pusillus, Apophysomyces elegans, Absidia elegans and Mucor racemosus are most common cause of the disease. ${ }^{10-14}$

\section{Clinical pathogenesis}

Mucormycetes mould can invade in the susceptible host via nostrils, mouth or burned/disrupted skin which results in rhino-orbito-cerebral, gastrointestinal or cutaneous wound infections. ${ }^{15}$ Mucormycosis also results in vascular thrombus and may lead to tissue necrosis. ${ }^{16}$

Studies suggested that Rhino cerebral Mucormycosis is most common among all other cases of Mucormycosis. It is most common in the patients with uncontrolled diabetes and leukemia. Sometimes progression of rhino-cerebral Mucormycosis may leads to central nervous system and it becomes fatal. The second most preferred site of infection could be lungs and sinuses. Mortality rate associated with lungs infection may be over $60 \% .^{17}$

\footnotetext{
* Corresponding author.

E-mail addresses: pharmanaveen@yahoo.co.in (N.K. Choudhary), director.brncop@meu.edu.in (A.K. Jain), rupesh.soni@meu.edu.in (R. Soni),neha.gahlot@meu. edu.in (N. Gahlot).
} 
In severe Covid-19 situation patient could develop dysfunction of immune system with decrease in lymphocyte counts and exponentially rise in inflammatory cytokines such as IL-6, IL-1 $\beta$, IFN- $\gamma$, MCP-1, IP-10, IL-4, IL-10 and Tumor necrosis factor (TNF) that leads to hyperinflammation in the lungs and some patients may leads to death. ${ }^{18,19}$ Due to the severity of hyperinflammation or viral load physicians preferred use of immunosuppressant or steroids as a life saving treatment in critically severe patients. A steroid reduces inflammation in the lungs besides these steroids also reduce immunity of the body and increases blood sugar level in both diabetic and normal patients. ${ }^{18}$ According to the physicians immuunosuppresed patients are more likely to be affected with Mucormycosis or Black fungus. ${ }^{20,21}$ (Fig. 1)

The entry of severe acute respiratory syndrome coronavirus 2 (SARSCoV-2) is possible via spike protein available on the envelope which binds with angiotensin converting enzyme 2 (ACE 2), which are available at pancreatic beta cells, lungs, kidney and small intestine. It is possible that entry of virus into pancreatic cells may damage beta cells and leads to insulin deficiency. ${ }^{22,23}$ Patients with hyperglycemia and ketoacidosis are more susceptible to get attacked by Mucormycosis moulds. ${ }^{24,25}$ Treatment of Covid-19 patient with immunosuppressant having uncontrolled diabetes mellitus and ketoacidosis are also at major risk for Mucormycosis as it leads to dysfunctional phagocytes causes impaired intracellular killing by oxidative and non-oxidative mechanism. ${ }^{26}$ (Fig. 2)

The pathogenesis of patients having diabetes mellitus in ketoacidosis also suggested that hyperglycemia and acidic $\mathrm{pH}$ (7.3-6.88) also leads to elevated free iron in the serum which is due to release of iron from the binding proteins. This free iron also promotes growth of Mucormycosis mould such as Rhizopus arrhizu, Rhizopus oryzae. ${ }^{27}$

Moreover patients receiving deferoxamine are also more susceptible to get attacked by Rhizopus species while deferoxamine act as iron chelator. Studies suggested that Xenosiderophore, Siderophores of fungus has higher affinity for Iron than deferoxamine, so they easily detach iron from deferoxamine and provide it to fungus. ${ }^{28,29}$

It was also pointed out that obese adipose tissues releases adipokines that modulate glucose metabolism by excessive release of inflammatory cytokines (IL-6, IL-8, TNF- $\alpha$ ) and causes hyperinflammation. ${ }^{30,31}$ Adipose tissues in obese patient also induce mitochondrial production of reactive oxygen species (ROS). ${ }^{32}$ In hyperglycemic state, higher level of ROS will cause increased glycosylation and activation of protein kinase
C. ${ }^{33}$ Therefore, Covid-19 patient with obesity are also more prone to get attacked by Mucormycosis.

Patients with solid organ or bone marrow transplantion, liver cirrhosis, neutropenia are also more susceptible to get infected with Mucormycosis. As these patients have lesser number of monocytes and neutrophils which has ability to inhibit mucormycetes mould. ${ }^{21,34,35}$ So here the inference is that Covid patient with lesser number of monocytes and meutrophils has higher probability to get infected by mucormycosis.

As discussed above, the probability of the development of Mucormycosis mould is mainly associated with patients suffering from diabetes mellitus, ketoacidosis, decreased immunity and patient's receiveing immunosuppressant/corticosteroids as in case of Covid-19. The source of developing or inoculation of Mucormycosis moulds is mainly accompanied by contamination with water and soil. ${ }^{36}$ In case of Covid-19 probably the source could be water for humidifier during oxygen therapy before inhaling inside by the patients. The infection can be life threatening and has a mortality rate of $38-80 \%$.

\section{Signs and symptoms}

During treatment or post Covid-19 patient's complaint for fever, headache, and reddish swollen skin over nose and around eyes all are the major signs and symptoms of Mucormycosis. ${ }^{37,38}$ Patients also reported visual abnormalities, eye swelling, ocular pain, facial edema and breathe shortening. Diabetic patients also reported for the symptoms of diplopia which is also the sign of infection. ${ }^{39}$ In scientific terminology sinus pain, proptosis, periorbital swelling, orbital apex syndrome and ulcer of the palate and cranial nerve palsy are the major symptoms of Mucormycosis infection. ${ }^{40}$

\section{Diagnosis}

Diagnosis of mucormycosis is a challenging task but based upon identification of characteristic symptoms, detailed patient history, thorough clinical evaluation and specialized tests dedicated physician can diagnose it. Mucormycosis doesn't respond to any antigen detection test as galactomannan antigen test is available for detection of aspergillosis. $^{41}$

Histopathology of infected tissue is also used to distinguish the Mucorales from Aspergillus or other hyaline molds as Mucorales
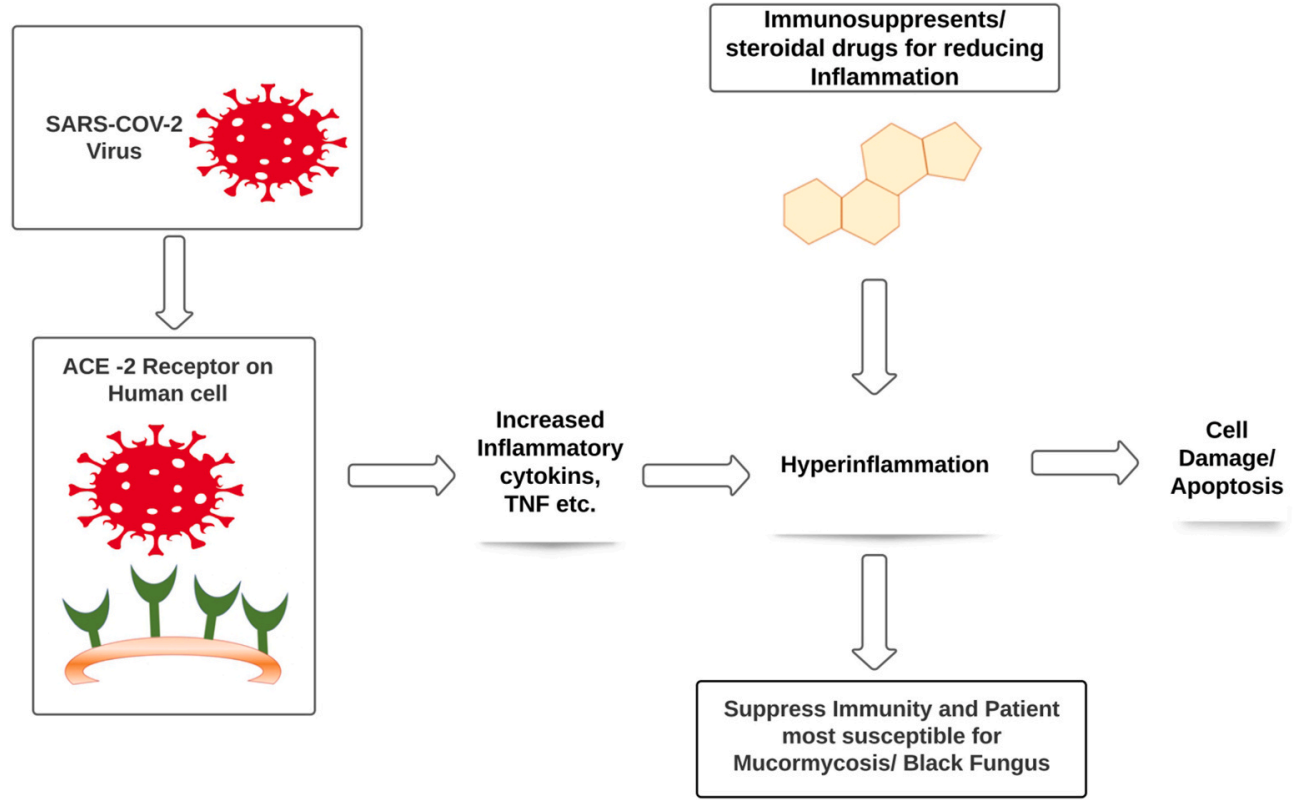

Fig. 1. In severe Covid-19 situation patient could develop dysfunction of immune system with decrease in lymphocyte counts and exponentially rise in inflammatory. 


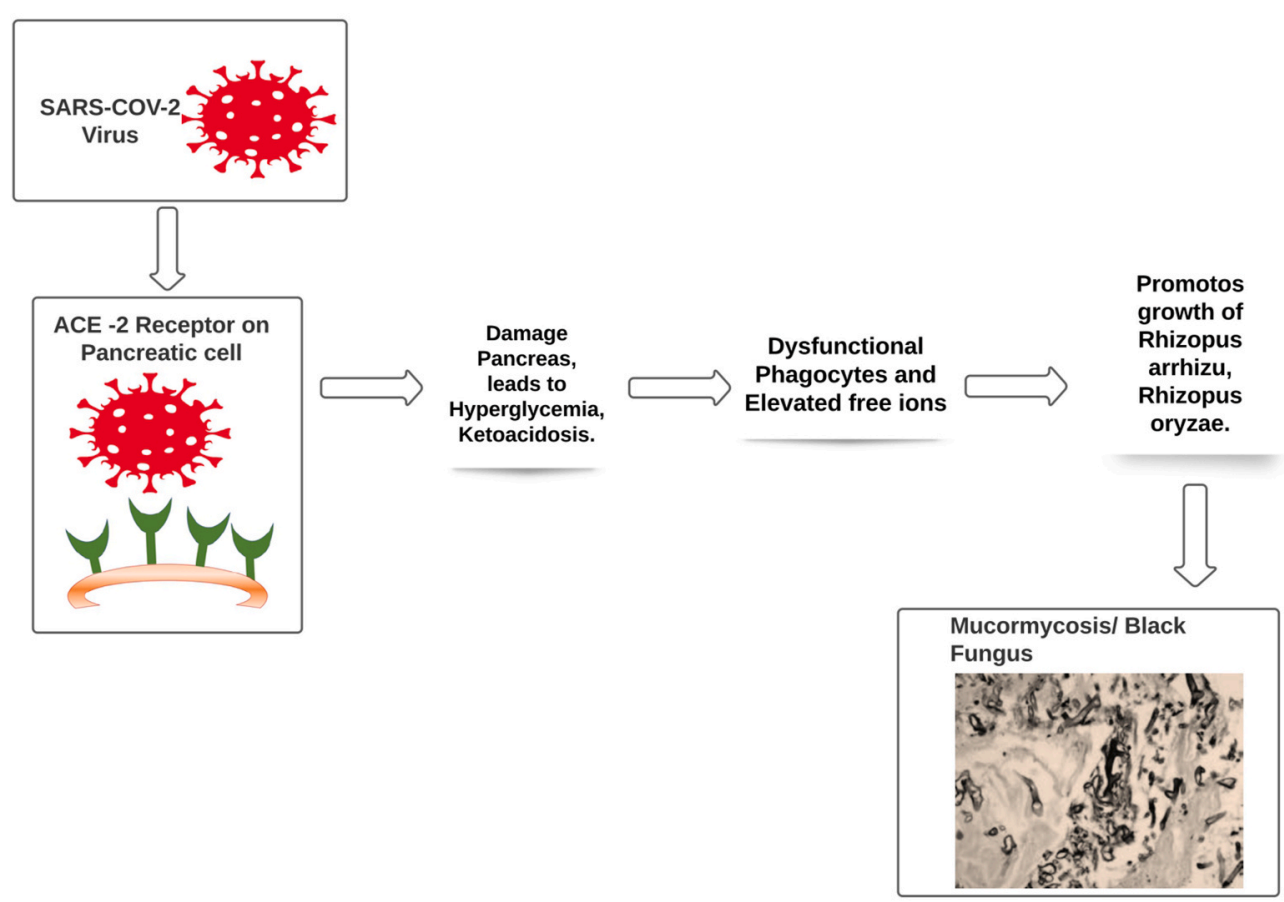

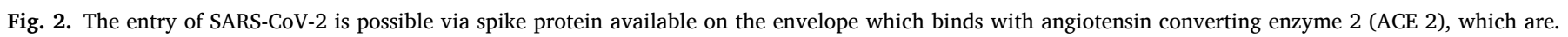

produce typical non-pigmented, wide $(5-20 \mu \mathrm{m})$, thin walled, ribbon like hyphae. ${ }^{41}$ Direct microscopy (wet mounts method) of infected tissue using fluorescent brighteners i.e. Blankophor, Calcofluor white with potassium hydroxide is also used for rapid diagnosis and visualization of characteristic fungal hyphae. Culture of specimen is also important method as mucorales are able to grow rapidly at temperature of 24-37 ${ }^{\circ} \mathrm{C}$ within a time frame of $24-48 \mathrm{~h}$. Tissue culture method allows identification to the level of genus and species. ${ }^{42}$

Milon $\mathrm{L}$ et al. reported early diagnosis and monitoring of mucormycosis by detection of circulating DNA in serum using quantitative polymerase chain reaction that are difficult to diagnose by histopathological examination. Reported method has good specificity with no cross amplification with other common fungal infection causing species such as Fusarium, Aspergillus and Scedosporium. Moreover, the qPCR method is also useful in the patients who cannot undergo biopsy or the patients with haematologic malignancies due to severe thrombocytopenia. ${ }^{43,44}$

\section{Treatment}

Early diagnosis, removal of predisposing factors, timely antifungal therapy with surgical removal of all infected tissues and adjunctive therapies are four major factors to eradicate Mucormycosis. ${ }^{45}$ Due to availability of limited tools early detection in $50 \%$ cases is suspicious and is only diagnosed after post-mortem. ${ }^{46}$ Only in case of rhino-cerebral and cutaneous infection it is possible to diagnose via imaging studies and nasal endoscopy. ${ }^{47}$ Million et al. reported a polymerase chain reaction (PCR) method which detects mucorales DNA in blood samples three days before Mucormycosis diagnosis. ${ }^{48}$ Therefore, If Covid -19 patient with diabetes report headache and visual abnormalities then patient must be evaluated for Mucormycosis via imaging studies and nasal endoscopy. Early detection in such case may save life because in later phase fungus may penetrate the cranium and may lead to death.

Removals or control of all predisposing factors are also necessary for proper treatment of Mucormycosis infection. As diabetes with ketoacidosis is the major problem among Indian patients so control over hyperglycemia with reversal of ketoacidosis may lead to reversal of mucorales to invade host tissues. ${ }^{39}$ In this respect a study suggested that use of Sodium bicarbonate with insulin may reverse diabetic ketoacidosis. ${ }^{49}$ Limited or no use of Immunosuppressant drugs mainly steroids and deferoxamine also strongly opposes the invasion of mucorales in the host tissues. $^{13}$

If possible, removal of infected tissues is the best possible treatment for the mucormycosis. However this is easier in some cases such as rhino-cerebral or cutaneous infection but it is impossible to operate in many cases such as pulmonary disease or if the virus invades cerebra. ${ }^{44}$ A study reported that early surgerical excision of infected sinuses in rhino-cerebral mucormycosis prevent the infection from invasion in eyes which results in higher cure rates of $85 \%$. In a study, it was also reported that mortality was reduced to $14 \%$ from $70 \%$ if surgery was performed with antifungal agents. ${ }^{45}$

In several studies it was found that use of Amphotericin B is preferred antifungal drug of choice for the treatment of mucormycosis infection. Liposomal amphotericin B with a low dose of $5 \mathrm{mg} / \mathrm{g}$ /day to higher dose of $10 \mathrm{mg} / \mathrm{kg} /$ day to cerebral infection patient is most preferred as of low toxicity and higher CNS penetration. ${ }^{51,52}$ However, the duration of treatment with Amphotericin B is still not properly reported and it was decided by the physician on the basis of underlying condition of the patient. Some reports proposed at least three weeks treatment with Amphotericin B and if radiological and clinical improvement was observed then further treatment is clubbed with triazoles such as posaconazole, isavuconazole, voriconazole etc. ${ }^{53,54}$

Studies revealed that posaconazole is the most prominent alternate of Amphotericin B for the treatment of Mucormycosis infection. ${ }^{54}$ Clinical studies in animal models indicate that posaconazole is more effective then itraconazole and less effective then amphotericin B. Intravenous or tablet dosage form provides enhanced bioavailability to posaconazole drug. 48 Significant in-vitro activity against mucorales has been reported for Itraconazole, a broad spectrum triazole but in clinical trials it fails to demotivate mucorales. Voriconazole failed to prove against mucorales in an in-vitro model. ${ }^{50,55,56}$ Therefore triazoles should not be considered as a first line agent against Mucormycosis.

In an experimental murine model, Caspofungin alone showed minimal activity against mucorales when tested in-vitro however in combination with amphotericin $B$ it shows synergistic effect. It has very less 
toxicity. In an in-vitro activity, low dose of Caspofungin found effective by inhibiting (1-3)- $\beta$-D-glucan synthetase enzyme expressed by Rhizopus oryzae. $^{57,58}$

Other adjunctive therapies include iron chelator other than deferoxamine. Iron chelators did not allow the fungus to take iron and not support its growth whereas deferoxamine promotes growth of moulds. ${ }^{59}$ Use of hyperbaric oxygen also suppresses the growth of Mucormycosis mould as higher pressure of oxygen improves the ability of neutrophils to the kill the moulds. ${ }^{60}$

\section{Conclusion}

In the current situation of Covid-19, immunosuppressant has been a major tool to combat the severity of hyperinflammation or viral load in Covid-19 patient, in consequence to it significantly increases the risk to get infected with mucormycosis infection. The risk to get infected with mucormycosis increases sharply with patients having uncontrolled diabetes, leukemia as well as ketoacidosis. Healthcare professionals must care about the previous history of patient while treating Covid-19 because patients with solid organ or bone marrow transplantion, liver cirrhosis, neutropenia are at more risk to get infected with mucormycosis. Patients must report early for any type of sign and symptoms of Mucormycosis such as complaint for fever, headache, and reddish swollen skin over nose and around eyes because early diagnosis and removal of infected part with antifungal therapy is the major tool to eradicate the infection. More research is needed for better prevention and control over the opportunistic mucormycosis infection in Covid-19 patient. Also more refinement is necessary for the use of immunosuppressant during Covid-19 treatment.

\section{Funding}

Nil.

\section{Declaration of competing interest}

Authors declare no conflict of interest.

\section{Acknowledgment}

The authors would like to thanks Management of B R Nahata College of Pharmacy, Mandsaur University, Mandsaur for their support during the review.

\section{References}

1 Ramteke S, Sahu BL. Novel coronavirus disease 2019 (COVID-19) pandemic: considerations for the biomedical waste sector in India. Case Studies in Chemical and Environmental Engineering. 2020;2:100029. https://doi.org/10.1016/j. cscee.2020.100029.

2 Andrews MA, Areekal B, Rajesh KR, et al. First confirmed case of COVID-19 infection in India: a case report. Indian J Med Res. 2020 May;151(5):490-492. https://doi.org/ 10.4103/ijmr.IJMR_2131_20.

3 https://en.wikipedia.org/wiki/COVID-19_pandemic_in_India.

4 Gandhi RT, Lynch JB, Rio CD. Mild or moderate covid-19. N Engl J Med. 2020;383: 1757-1766. https://doi.org/10.1056/NEJMcp2009249.

5 Apicella M, Campopiano MC, Mantuano M, Mazoni L, Coppelli A, Prato SD. COVID19 in people with diabetes: understanding the reasons for worse outcomes. Lancet Diabetes Endocrinol. 2020;8:782-792. https://doi.org/10.1016/S2213-8587(20) 30238-2.

6 Salehi M, Ahmadikia K, Badali H, Khodavaisy S. Opportunistic fungal infections in the epidemic area of COVID-19: a clinical and diagnostic perspective from Iran. Mycopathologia. 2020;185:607-611. https://doi.org/10.1007/s11046-020-00472-7.

7 Chowdhary A, Tarai B, Singh A, Sharma A. Multidrug-resistant Candida auris infections in critically Ill coronavirus disease patients, India, April-July 2020. Emerg Infect Dis. 2020;26:2694-2696. https://doi.org/10.3201/eid2611.203504.

8 Sarkar S, Gokhale T, Choudhury SS, Deb AK. COVID-19 and orbital mucormycosis. Indian J Ophthalmol. 2021;69:1002-1004. https://doi.org/10.4103/ijo.IJO_3763_20.

9 Afroze SN, Korlepara R, Rao GV, Madala J. Mucormycosis in a diabetic patient: a case report with an insight into its pathophysiology. Contemp Clin Dent. 2017 Oct-Dec;8 (4):662-666. https://doi.org/10.4103/ccd.ccd_558_17.
11 https://punemirror.indiatimes.com/news/india/india-reports-8848-mucormycosis -cases/articleshow/82864576.cms.

12 Prabhu RM, Patel R. Mucormycosis and entomophthoramycosis: a review of the clinical manifestations, diagnosis and treatment. Clin Microbiol Infect. 2004;10(suppl 1):31-47. https://doi.org/10.1111/j.1470-9465.2004.00843.x.

13 Ribes JA, Vanover-Sams CL, Baker DJ. Zygomycetes in human disease. Clin Microbiol Rev. 2000;13:236-301. https://doi.org/10.1128/CMR.13.2.236.

14 Angali RK, Jeshtadi A, Namala VA, Gannepalli A. Fatal rhino-orbito-cerebral mucormycosis in a healthy individual. J Oral Maxillofac Pathol. 2014 Sep-Dec;18(3): 460-463. https://doi.org/10.4103/0973-029X.151355.

15 Mohindra S, Mohindra S, Gupta R, Bakshi J, Gupta SK. Rhinocerebral mucormycosis: the disease spectrum in 27 patients. Mycoses. 2007;50:290-296. https://doi.org/ 10.1111/j.1439-0507.2007.01364.x.

16 Rapidis AD. Orbitomaxillary mucormycosis (zygomycosis) and the surgical approach to treatment: perspectives from a maxillofacial surgeon. Clin Microbiol Infect. 2009;15 (Suppl. 5):98-102. https://doi.org/10.1111/j.1469-0691.2009.02989.x.

17 Spellberg B, Edwards Jr J, Ibrahim A. Novel perspectives on mucormycosis: pathophysiology, presentation, and management. Clin Microbiol Rev. 2005;18(3): 556-569. https://doi.org/10.1128/CMR.18.3.556-569.2005.

18 Zhou Q, Chen V, Shannon CP, et al. Interferon- $\alpha 2 b$ treatment for COVID-19. Front. Immunol. 2020 May 15;11:1061. https://doi.org/10.3389/fimmu.2020.01061.

19 Song P, Li W, Xie J, Hou Y, You C. Cytokine storm induced by SARS-CoV-2. Clinica Chimica Acta. 2020 Oct;509:280-287. https://doi.org/10.1016/j.cca.2020.06.017.

20 Shang Y, Pan C, Yang X, et al. Management of critically ill patients with COVID-19 in ICU: statement from front-line intensive care experts in Wuhan, China. Ann. Intensive Care. 2020;10:73. https://doi.org/10.1186/S13613-020-00689-1.

21 Pak J, Tucci VT, Vincent AL, Sandin RL, Greene JN. Mucormycosis in immunochallenged patients. J Emerg Trauma Shock. 2008;1(2):106-113. https://doi. org/10.4103/0974-2700.42203.

22 Bourgonje AR, Abdulle AE, Timens W, et al. Angiotensin-converting enzyme 2 (ACE2), SARS-CoV-2 and the pathophysiology of coronavirus disease 2019 (COVID19). J. Pathol. 2020;251:228-248. https://doi.org/10.1002/path.5471.

23 Zou X, Chen K, Zou J, Han P, Hao J, Han Z. The single-cell RNA-seq data analysis on the receptor ACE2 expression reveals the potential risk of different human organs vulnerable to Wuhan 2019-nCoV infection. Front Med. 2020;14:185-192. https:// doi.org/10.1007/s11684-020-0754-0.

24 Maertens J, Demuynck H, Verbeken EK, et al. Mucormycosis in allogeneic bone marrow transplant recipients: report of five cases and review of the role of iron overload in the pathogenesis. Bone Marrow Transplant. 1999;24:307-312. https:// doi.org/10.1038/sj.bmt.1701885.

25 Kontoyiannis DP, Wessel VC, Bodey GP, Rolston KV. Zygomycosis in the 1990s in a tertiary-care cancer center. Clin Infect Dis. 2000;30:851-856. https://doi.org/ 10.1086/313803.

26 Ahmadikia K, Hashemi SJ, Khodavaisy S, et al. The double-edged sword of systemic corticosteroid therapy in viral pneumonia: a case report and comparative review of influenza-associated mucormycosis versus COVID-19 associated Mucormycosis. Mycoses. 2021:1-11. https://doi.org/10.1111/myc.13256, 00.

27 Ibrahim AS, Spellberg B, Walsh TJ, Kontoyiannis DP. Pathogenesis of mucormycosis. Clinical Infectious Diseases. 2012;54(S1):S16-S22. https://doi.org/10.1093/cid/ cir865.

28 Locht MD, Boelaert JR, Schneider YJ. Iron uptake from ferrioxamine and from ferrirhizoferrin by germinating spores of Rhizopus microspores. Biochem Pharmacol. 1994;47:1843-1850. https://doi.org/10.1016/0006-2952(94)90314-x.

29 Boelaert JR, Locht MD, Cutsem JV, et al. Mucormycosis during deferoxamine therapy is a siderophore mediated infection: in-vitro and in-vivo animal studies. $J$ Clin Invest. 1993;91:1979-1986. https://doi.org/10.1172/JCI116419.

30 Ouchi N, Parker JL, Lugus JJ, Walsh K. Adipokines in inflammation and metabolic disease. Nature Reviews Immunology. 2011;11(2):85-97. https://doi.org/10.1038/ nri2921.

31 Eder K, Baffy N, Falus A, Fulop AK. The major inflammatory mediator interleukin-6 and obesity. Inflammation Research. 2009;58(11):727-736. https://doi.org/10.1007/ s00011-009-0060-4.

32 Manna P, Jain SK. Obesity, oxidative stress, adipose tissue dysfunction, and the associated health risks: causes and therapeutic strategies. Metab Syndr Relat Disord. 2015 Dec 1;13(10):423-444. https://doi.org/10.1089/met.2015.0095.

33 Brownlee M. The pathobiology of diabetic complications: a unifying mechanism. Diabetes. 2005;54:1615-1625. https://doi.org/10.2337/diabetes.54.6.1615.

34 Prakash H, Chakrabarti A. Global epidemiology of mucormycosis. J. Fungi. 2019;5: 26. https://doi.org/10.3390/jof5010026.

35 Persichino JG, Can AD, Van TT, Matthews MN, Filler SG. Invasive pulmonary mucormycosis and aspergillosis in a patient with decompensated hepatic cirrhosis. Med. Mycol. Case Rep. 2018;21:12-15. https://doi.org/10.1016/j. mmcr.2018.03.004.

36 Novak Babic M, Gunde-Cimerman N, Vargha M, et al. Fungal contaminants in drinking water regulation? A tale of ecology, exposure, purification and clinical relevance. Int J Environ Res Public Health. 2017;14(6):636. https://doi.org/10.3390/ ijerph14060636.

37 AK AK, Gupta V. StatPearls Publishing; 2021 Jan. Rhino-orbital Cerebral Mucormycosis. [Updated 2021 May 1]. In: StatPearls [Internet]. Treasure Island (FL) https://www.ncbi.nlm.nih.gov/books/NBK557429/. Available from:.

38 https://science.thewire.in/the-sciences/covid-19-and-black-fungus-what-is-muco rmycosis/.

39 Spellberg B, Edwards Jr J, Ibrahim A. Novel perspectives on mucormycosis: pathophysiology, presentation, and management. Clin Microbiol Rev. 2005;18(3): 556-569. https://doi.org/10.1128/CMR.18.3.556-569.2005. 
40 Mukherjee B, Raichura ND, Alam MS. Fungal infections of the orbit. Indian $J$ Ophthalmol. 2016;64(5):337-345. https://doi.org/10.4103/0301-4738.185588.

41 Ribes JA, Vanover-Sams CL, Baker DJ. Zygomycetes in human disease. Clin Microbiol Rev. 2000;13:236-301. https://doi.org/10.1128/CMR.13.2.236.

42 Walsh TJ, Gamaletsou MN, McGinnis MR, Hayden RT, Kontoyiannis DP. Early clinical and laboratory diagnosis of invasive pulmonary, extrapulmonary and disseminated mucormycosis (zygomycosis). Clin. Infect. Dis. 2012;54:S55-S60. https://doi.org/10.1093/cid/cir868.

43 Millon L, Larosa F, Lepiller Q, et al. Quantitative polymerase chain reaction detection of circulating DNA in serum for early diagnosis of mucormycosis in immunocompromised patients. Clin Infect Dis. 2013;56:e95-e101.

44 Millon L, Herbrecht R, Grenouillet F, et al. Early diagnosis and monitoring of mucormycosis by detection of circulating DNA in serum: retrospective analysis of 44 cases collected through the French Surveillance Network of Invasive Fungal Infections (RESSIF). Clin Microbiol Infect. 2016;22(9):810.E1-810.E8.

45 Nithyanandam S, Jacob MS, Battu RR, Thomas RK, Correa MA, D’Souza O. Rhinoorbito-cerebral mucormycosis. A retrospective analysis of clinical features and treatment outcomes. Indian J Ophthalmol. 2003;51:231-236.

46 Mori T, Egashira M, Kawamata N, et al. Zygomycosis: two case reports and review of reported cases in the literature in Japan. Nihon Ishinkin Gakkai Zasshi. 2003;44: 163-179. https://doi.org/10.3314/jjmm.44.163.

47 Khor BS, Lee MH, Leu HS, Liu JW. Rhinocerebral mucormycosis in taiwan. J Microbiol Immunol Infect. 2003;36:266-269.

48 Millon L, LaRosa F, Lepiller Q, et al. Quantitative polymerase chain reaction detection of circulating DNA in serum for early diagnosis of mucormycosis in immunocompromised patients. Clin. Infect. Dis. 2013;56:e95-e101. https://doi.org/ 10.1093/cid/cit094.

49 Gebremariam T, Lin L, Liu M, et al. Bicarbonate correction of ketoacidosis alters hostpathogen interactions and alleviates mucormycosis. J Clin Invest. 2016;126: 2280-2294. https://doi.org/10.1172/JCI82744.

50 Bouza E, Munoz P, Guinea J. Mucormycosis: an emerging disease? Clin Microbiol Infect. 2006;12(suppl 7):7-23. https://doi.org/10.1111/j.1469-0691.2006.01604.x.

51 Barron MA, Lay M, Madinger NE. Surgery and treatment with high-dose liposomal amphotericin B for eradication of craniofacial zygomycosis in a patient with Hodgkin's disease who had undergone allogeneic hematopoietic stem cell transplantation. J Clin Microbiol. 2005;43:2012-2014. https://doi.org/10.1128/ JCM.43.4.2012-2014.2005.

52 Cagatay AA, Oncu SS, Calangu SS, Yildirmak TT, Ozsut HH, Eraksoy HH. Rhinocerebral mucormycosis treated with 32 gram liposomal amphotericin B and incomplete surgery: a case report. BMC Infect Dis. 2001;1:22. https://doi.org/ 10.1186/1471-2334-1-22.

53 Kontoyiannis DP, Lewis RE. How I treat mucormycosis. Blood. 2011;118(5): 1216-1224. https://doi.org/10.1182/blood-2011-03-316430.

54 Cornely OA, Alastruey IA, Arenz D, et al. Global guideline for the diagnosis and management of mucormycosis: an initiative of the European confederation of medical mycology in cooperation with the mycoses study group education and research consortium. Lancet Infect. Dis. 2019;19:e405-e421.

55 Dannaoui E, Meis JF, Loebenberg D, Verweij PE. Activity of posaconazole in treatment of experimental disseminated zygomycosis. Antimicrob Agents Chemother. 2003;47:3647-3650. https://doi.org/10.1128/AAC.47.11.3647-3650.2003.

56 Pfaller MA, Messer SA, Hollis RJ, Jones RN. Antifungal activities of posaconazole, ravuconazole, and voriconazole compared to those of itraconazole and amphotericin B against 239 clinical isolates of Aspergillus spp. and other filamentous fungi: report from SENTRY Antimicrobial Surveillance Program. Antimicrob Agents Chemother. 2002;46:1032-1037. https://doi.org/10.1128/AAC.46.4.1032-1037.2002, 2000.

57 Spellberg B, Fu Y, Edwards Jr JE, Ibrahim AS. Combination therapy with amphotericin B lipid complex and caspofungin acetate of disseminated zygomycosis in diabetic ketoacidotic mice. Antimicrob Agents Chemother. 2005;49:830-832. https://doi.org/10.1128/AAC.49.2.830-832.2005.

58 Ibrahim AS, Bowman JC, Avanessian V, et al. Caspofungin inhibits Rhizopus oryzae 1,3-beta-D-glucan synthase, lowers burden in brain measured by quantitative PCR, and improves survival at a low but not a high dose during murine disseminated zygomycosis. Antimicrob Agents Chemother. 2005;49:721-727. https://doi.org/ 10.1128/AAC. 49.2.721-727.2005.

59 Boelaert JR, Cutsem JV, Locht DM, Schneider YJ, Crichton RR. Deferoxamine augments growth and pathogenicity of Rhizopus, while hydroxypyridinone chelators have no effect. Kidney Int. 1994;45:667-671. https://doi.org/10.1038/ki.1994.89.

60 Ferguson BJ, Mitchell TG, Moon R, Camporesi EM, Farmer J. Adjunctive hyperbaric oxygen for treatment of rhinocerebral mucormycosis. Rev Infect Dis. 1988 May-Jun; 10(3):551-559. https://doi.org/10.1093/clinids/10.3.551. DOI: 10.1093/clinids/ 10.3.551. 